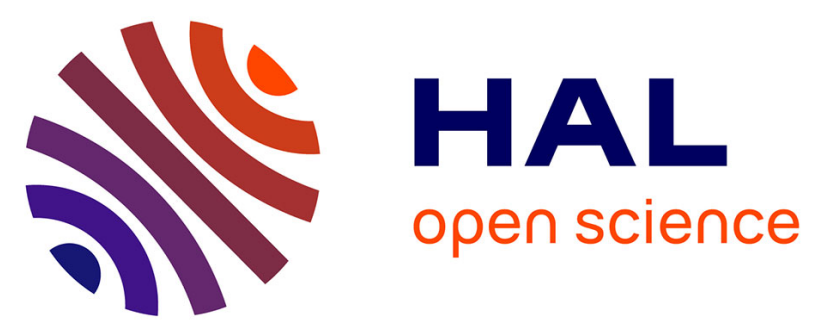

\title{
Risk of road traffic injuries for pedestrians, cyclists, car occupants and powered two-wheel users, based on a road trauma registry and travel surveys, Rhône, France
}

Stéphanie Blaizot, Francis Papon, Mohamed Mouloud Haddak, Emmanuelle Amoros

\section{To cite this version:}

Stéphanie Blaizot, Francis Papon, Mohamed Mouloud Haddak, Emmanuelle Amoros. Risk of road traffic injuries for pedestrians, cyclists, car occupants and powered two-wheel users, based on a road trauma registry and travel surveys, Rhône, France. TRA - Transport Research Arena, Apr 2014, Paris, France. 10p. hal-01066898

\section{HAL Id: hal-01066898 https://hal.science/hal-01066898}

Submitted on 22 Sep 2014

HAL is a multi-disciplinary open access archive for the deposit and dissemination of scientific research documents, whether they are published or not. The documents may come from teaching and research institutions in France or abroad, or from public or private research centers.
L'archive ouverte pluridisciplinaire HAL, est destinée au dépôt et à la diffusion de documents scientifiques de niveau recherche, publiés ou non, émanant des établissements d'enseignement et de recherche français ou étrangers, des laboratoires publics ou privés. 


\title{
Risk of road traffic injuries for pedestrians, cyclists, car occupants and powered two-wheel users, based on a road trauma registry and travel surveys, Rhône, France
}

\author{
Stéphanie Blaizot ${ }^{\mathrm{a} b \mathrm{c}}$, Francis Papon $^{\mathrm{d}}$, Mohamed Mouloud Haddak ${ }^{\mathrm{abc}}$, \\ Emmanuelle Amoros ${ }^{\mathrm{a} b \mathrm{c}} 1$ \\ ${ }^{a}$ Université de Lyon, F-69000, Lyon, France \\ ${ }^{b}$ French Institute of Science and Technology for Transport, Development and Networks (IFSTTAR), Epidemiological \\ Research and Surveillance Unit in Transport, Occupation and Environment (UMRESTTE), F-69500, Bron \\ ${ }^{c}$ Université Lyon 1, F-69000, Lyon, France \\ ${ }^{d}$ Université Paris-Est, French Institute of Science and Technology for Transport, Development and Networks (IFSTTAR), \\ Department of Transport Economics and Sociology (DEST), F-93166 Noisy-le-Grand, France
}

\begin{abstract}
We estimate the risk of traffic injuries as the ratio of amount of casualties and mobility. Crash data come from a road trauma Registry, including outpatients and inpatients, on the Rhône county (1.6 M inhabitants, including Lyon). These data are far more complete than police data, in particular for cyclist crashes. Mobility comes from travel surveys. Compared with car occupants and with regards to time spent travelling, the all-injury rate was twice lower for pedestrians, 8 times higher for cyclists, and 42 times higher for powered two-wheel (PTW) riders. For serious injuries, compared to car occupants, the risk is respectively 2, 16 and 120 times higher for pedestrians, cyclists and PTW users. For car occupants, pedestrians and cyclists, the age group 18-25 years had the highest all-injury rate. For cyclists, the injury rates seemed higher in non-dense areas than in dense areas. Between 1996-1997 and 2005-2006 and with regards to time spent travelling, the all-injury, and serious-injury rates seems to have decreased for car occupants and cyclists, and even more so for cyclists.
\end{abstract}

Keywords: mobility; travel survey; road injury risk; road trauma registry; trends ; pedestrians; cyclists ; car occupants; powered two-wheel users

\section{Résumé}

Nous estimons le risque de blessés de la route comme le ratio entre quantité de blessés et mobilité. Les données d'accident proviennent d'un registre médical des blessés de la route, incluant les hospitalisés et ceux traités aux urgences, sur le département du Rhône (1,6 M d'habitants, incluant Lyon). Ces données sont bien plus complètes que les données policières, surtout pour les cyclistes. La mobilité est mesurée par des enquêtes déplacements. Comparé aux automobilistes, et en termes d'heures passées, le risque de blessures toutes gravités est 2 fois plus faible pour les piétons, 8 fois plus élevé pour les cyclistes et 42 fois plus pour les usagers de deux-roues motorisés (2RM). Pour les blessures graves, comparé aux automobilistes, le risque est respectivement 2, 16 et 120 fois plus chez les piétons, cyclistes et 2RM. Chez les automobilistes, piétons et cyclistes, les 18-25 ans ont le risque le plus élevé. Chez les cyclistes le risque semble plus élevé en zones non-denses. Entre 1996-97 et 200506, le risque d'être blessé semble diminuer chez les automobilistes et plus encore chez les cyclistes.

Mots-clé: mobilité; enquête déplacements; risque d'accident de la route ; registre des blessés de la route ; évolutions ; piétons ; cyclistes ; automobilistes, usagers de deux-roues motorisés

\footnotetext{
${ }^{1}$ Corresponding author: Emmanuelle Amoros. Tel .:+00-33-(0)4-72-14-25-33; fax: +00-33-(0)4-72-37-68-37 emmanuelle.amoros@ifsttar.fr
} 


\section{Introduction}

In some of France's major cities (Paris, Lyon, Lille ...), there has been an increase in cycling, mostly as a means of transport (Papon \& De Solère 2010). Cycling is encouraged in the framework of sustainable development and for better health through physical activity. We therefore need to know more about cyclist road risk, compared to other road user types.

In France and in most countries, crash data are provided by the police. However, police crash data suffer from under-reporting and selection bias. This under-reporting varies mostly with injury severity, the presence/absence of a crash opponent and the road user type (Hauer \& Hakkert 1988; Elvik \& Mysen 1999). Crashes involving cyclists are particularly less reported (Langley, Dow et al. 2003; Amoros, Martin et al. 2006). In the Rhône County (population of 1.6 million inhabitants, with Lyon being the main city), a medical registry provides a second source of data, far more complete than police data (Amoros, Martin et al. 2006). Indeed, over the period 2004-2007, police crash data recorded about 155 injured cyclists and the medical Registry recorded 1230 injured cyclists, per year. This medical source is used here.

The objective of the present study is to estimate injury rates in the Rhône County, using medical crash data and travel surveys. Rates are estimated for car occupants, pedestrians, cyclists and powered two-wheeler (PTW) riders, separately for three injury categories (all-injury, hospitalization, and serious-injury) and by gender, age groups and location (dense vs. non-dense areas). The exposure measures are number of trips, distance travelled or time spent travelling with a given means of transport. These are obtained from a regional travel survey. This survey is however restricted to the winter period of the years 2005 and 2006 and to typical weekdays. To correct for this, seasonality ratios were introduced, which were estimated from the 2007-2008 national transport survey. Trends of the injury rates are also studied, between the 2005-2006 time point and the 1994-1995 time point (previous regional travel survey)

\section{Material and methods}

\subsection{Hospital-based crash data: the Rhône road trauma registry}

A road trauma registry has been in operation since 1996 and has been certified by the relevant French authority (Comité National des Registres). It covers all casualties from road crashes in the Rhône County, who benefit from medical care in health facilities. All health care facilities (from public and private hospitals) in the County and its surrounding area, which receive crash victims, participate: about 280 health units ranging from prehospital emergency care, emergency departments, intensive care units, surgery units, etc. to rehabilitation departments. Injury assessment is based on all diagnoses established in the different health services a casualty may have visited. Diagnoses are coded with the Abbreviated Injury Scale (AIS) which includes a severity score: $1=$ minor, $2=$ moderate, $3=$ serious, $4=$ severe, $5=$ critical and $6=$ beyond treatment (AAAM 1990). In this study, the MAIS (Maximum AIS) is used (maximum severity code in case of multiple injuries). Three injury categories are studied: all-injury (whatever the severity), hospitalization, and serious-injury (MAIS $3+$ ).

\subsection{The regional travel survey (RTS)}

A regional travel survey (RTS) provides data on travel practices of the resident population of the region. Mobility is measured through all the trips made the day before the interview, for all means of transport used. A trip is defined as going from one place to another, where an activity is performed (round trips are split into two one-way trips). For each trip, the following data are collected: means of transport used, origin and destination locations of the trip, and times of departure and arrival. Distance is a posteriori estimated from an origindestination matrix.

The most recent RTS in the Rhône County, was carried out between November 2005 and April 2006, on weekdays, outside school and public holidays. Three exposure measures were estimated: number of trips, distance travelled and time spent travelling. In the results, we favor number of hours spent travelling. The first reason is that time-budget is less elastic than distance-budget: time spent travelling on a day is quite similar between road users, whatever the type; whereas distance travelled on a day varies much by type of road user. We hence think that time spent travelling makes comparisons more relevant. The second reason is that it allows comparisons with injury risk of other activities (e.g. sport and do-it-yourself). 


\subsection{Seasonality correction}

Given that the RTS was carried out on weekdays (i.e. excluding weekends), outside school and public holidays, in the winter period, we sought to correct for this in order to have year-round estimates. We introduced seasonality ratios; these were estimated from the national household travel survey (NTS) performed in France in 2007-2008. We split this survey into two periods: 1) the 'RTS' period, i.e. November to April on weekdays, outside school and public holidays; and 2) the 'outside RTS' period, i.e. the rest of the year. We then divided the amount of each mobility measure associated to the 'outside RTS' period by the total amount of the exposure measure associated to the 'RTS' period to create seasonality ratios. These ratios were then applied to the mobility estimated from the RTS to obtained two full year data between January 2005 and December 2006.

\subsection{Location: dense and non-dense areas}

The Rhône County being quite urbanized, a variable 'dense areas / non-dense areas' was created. This distinction enables us to obtain results that do not depend on this characteristic. Moreover, this variable may be used as a proxy to identify different groups of cyclists according to their type of bicycle use: most sport or leisure cycling take place in non-dense areas, and most cycling as a means of transport takes place in dense areas (Amoros, Chiron et al. 2011).

We defined municipalities as being 'dense areas' if their "ZAUER" category (such as defined by INSEE- the French National Institute of Statistics and Economic Studies) was "urban cluster" with a further population density of over 500 persons per $\mathrm{km}^{2}$ or a population of over 5,000, or if their ZAUER category was "rural employment cluster" (more than 5,000 jobs). All other locations were considered to be 'non-dense areas'.

For the crash data, the crash location was classified into 'dense' or 'non-dense' areas. In the mobility data, trips were classified into 'dense' or 'non-dense' areas based on the origin and destination locations; if these two differed, the characteristic of the destination location was considered.

\subsection{Injury rates}

For each type of user (car occupants, pedestrians, cyclists, PTW riders), all-injury (whatever the severity), hospitalization, and serious-injury (MAIS 3+) rates were estimated. These rates were estimated by dividing the number of injuries by the exposure measurement, and scaled per 1 million trips, kilometers or hours. Rates by gender, age group and location ('dense areas' and 'non-dense areas') were estimated separately for each type of user (except for PTW riders because of insufficient mobility data). Only residents of the Rhône County were included in the study. Crashes and trips were also restricted to the Rhône County.

The variability in the estimation of mobility and seasonality ratios could not be taken into account, because of complex design surveys. This means that the tests may lead to conclude to a difference too often.

\subsection{Trends of injury rates}

To study the trends of these injury rates, the last two RTSs were used. However, the previous RTS, performed in 1994-1995, was restricted to Greater Lyon (Lyon and its suburbs, mostly urban). This survey was also carried out in the winter period and on weekdays. To correct for this, seasonality ratios from the previous national travel survey (1993-1994) were used.

The trends for pedestrians could not be studied because the 1994-1995 regional survey did not investigate all types of walking (e.g. walking for transfer between two means of transport). The Rhone road trauma registry started in 1996; injury rates are estimated on 1996-1997, using crash data of the years 1996-1997 and mobility data of the years 1994-1995, making the (reasonable) assumption that mobility data did not change much between these 2 years.

\section{Results and interpretation}

\subsection{Seasonality ratios}

For car occupants, the seasonality ratios were around $0.7-0.8$; for pedestrians, they were around $0.7-0.9$. It means that exposure in the 'outside RTS' period was slightly lower than in the 'RTS' period (i.e. November to April on 
weekdays, outside school and public holidays). This might be explained by less commuting trips in summer and week-ends.

For cyclists, the seasonality ratios were between 1.4 and 1.6. These ratios, higher than 1 , can be explained by a higher bicycle use when weather conditions are good; the use is thus higher during summer than in winter. The bicycle use seemed similar on weekdays and on weekend days. For PTW riders, the seasonality ratios were between 1.2 and 1.5. These ratios, higher than 1, can also be explained by the fact that PTW use is dependent on good weather conditions.

\subsection{Injury rates}

\subsubsection{Injury rates by type of road user}

The all-injury rates are given in Table 1. Compared with car occupants and with regards to time spent travelling, pedestrians had a half lower rate (univariate analysis, $p$-value $<0.01)$, cyclists had an 8 times higher rate $(\mathrm{p}<0.01)$, and PTW riders had an about 42 times higher rate $(\mathrm{p}<0.01)$. In the multivariate analyses adjusted on type of road user, gender, age groups and location, cyclists had a 14 times higher injury ratio $(\mathrm{CI}=[9.5 ; 20.6])$ and pedestrians had a half lower rate $(\mathrm{CI}=[0.4 ; 0.7])$, compared to car occupants, all other things being equal (Table 2). In these analyses, the adjustment increases the ratio between car occupants and cyclists due to the adjustment on gender, as women, a minority in cyclists, appeared to have a higher risk (Table 3).

Table 1. All-injury rates, according to mobility measure, and ratios by type of road user, gender, age and location; medical Registry and Road Travel Survey corrected for seasonality, Rhône County, 2005-2006

\begin{tabular}{|c|c|c|c|c|c|c|c|c|}
\hline & & \multicolumn{2}{|c|}{$\begin{array}{c}\text { Car occupants } \\
N=6286\end{array}$} & \multicolumn{2}{|c|}{$\begin{array}{c}\text { Pedestrians } \\
N=1513\end{array}$} & \multicolumn{2}{|c|}{$\begin{array}{l}\text { Cyclists } \\
N=2228\end{array}$} & \multirow{2}{*}{$\begin{array}{c}\text { PTW riders } \\
N=3776 \\
\text { Rate }\end{array}$} \\
\hline & & Rate & Ratio & Rate & Ratio & Rate & Ratio & \\
\hline & & \multicolumn{7}{|c|}{ Per 1 million hours } \\
\hline & All & 12.83 & & 5.06 & & 99.41 & & 541.08 \\
\hline \multirow[t]{2}{*}{ Gender } & Male (ref) & 11.38 & 1.0 & 5.57 & 1.0 & 98.70 & 1.0 & - \\
\hline & Female & 14.50 & 1.3 & 4.59 & 0.8 & 96.28 & 1.0 & - \\
\hline \multirow[t]{5}{*}{ Age group } & $05-14$ & 5.55 & 0.5 & 8.06 & 2.0 & 110.03 & 1.6 & - \\
\hline & $14-18$ & 10.53 & 1.0 & 4.15 & 1.0 & 107.08 & 1.6 & - \\
\hline & $18-25$ & 48.39 & 4.5 & 7.38 & 1.8 & 142.29 & 2.1 & - \\
\hline & $25-65$ (ref) & 10.74 & 1.0 & 4.03 & 1.0 & 68.95 & 1.0 & - \\
\hline & $65+$ & 6.40 & 0.6 & 5.04 & 1.3 & 91.46 & 1.3 & - \\
\hline \multirow[t]{6}{*}{ Location } & Dense areas (ref) & 12.67 & 1.0 & 5.00 & 1.0 & 94.22 & 1.0 & - \\
\hline & Non-dense areas & 13.62 & 1.1 & 6.24 & 1.2 & 186.04 & 2.0 & - \\
\hline & & \multicolumn{7}{|c|}{ Per 1 million trips } \\
\hline & All & 3.72 & & 0.58 & & 29.73 & & 152.28 \\
\hline & & \multicolumn{7}{|c|}{ Per 1 million kilometers } \\
\hline & All & 0.48 & & 1.29 & & 11.30 & & 14.88 \\
\hline
\end{tabular}

PTW: powered two-wheeler; ref=reference group; - Insufficient data to estimate rates

The hospitalization rates are given in Table 4. Compared with car occupants and with regards to time spent travelling, cyclists had a 12 times higher rate $(\mathrm{p}<0.01)$ and PTW riders had an about 80 times higher rate $(p<0.01)$; rates for pedestrians and car occupants were similar $(p=0.20)$. 
Table 2. Multivariate analysis for the number of all-injury adjusted for type of road users, gender, age groups and location, with regards to time spent travelling; medical Registry and RTS corrected for seasonality, Rhône County, 2005-2006

\begin{tabular}{llcc}
\hline & & Injury ratio & $\mathbf{9 5 \%}$ CI \\
\hline Type of road user & Car occupants (ref) & 1 & - \\
& Pedestrians & $\mathbf{0 . 5 0}$ & {$[\mathbf{0 . 3 5} \mathbf{0 . 7 3 ]}$} \\
Cyclists & $\mathbf{1 3 . 9 8}$ & {$[\mathbf{9 . 5 0 ;} \mathbf{2 0 . 5 6 ]}$} \\
Gender & Male (ref) & 1 & - \\
\multirow{3}{*}{ Age group (years) } & Female & 1.23 & {$[0.90 ; 1.68]$} \\
& $05-14$ & 1.27 & {$[0.79 ; 2.05]$} \\
& $14-18$ & 1.13 & {$[0.69 ; 1.85]$} \\
& $18-25$ & $\mathbf{3 . 9 1}$ & {$[\mathbf{2 . 4 4 ;} \mathbf{6 . 2 8}]$} \\
\multirow{2}{*}{ Location } & $25-65$ (ref) & 1 & - \\
& $65+$ & 0.86 & {$[0.53 ; 1.39]$} \\
& Dense areas (ref) & 1 & - \\
\hline
\end{tabular}

Table 3. Multivariate analyses for the number of all-injury by type of road user adjusted for gender, age groups and location, with regards to time spent travelling; medical Registry and RTS corrected for seasonality, Rhône County, 2005-2006

\begin{tabular}{l|l|cc|cc|cc|}
\hline & & \multicolumn{3}{|c|}{ Car occupants } & \multicolumn{2}{c|}{ Pedestrians } & \multicolumn{2}{c|}{ Cyclists } \\
& & $I R$ & $95 \% C I$ & $I R$ & $95 \% C I$ & $I R$ & $95 \% C I$ \\
\hline Gender & Male (ref) & 1 & - & 1 & - & 1 & - \\
\multirow{3}{*}{ Age group (years) } & Female & 1.02 & {$[0.84 ; 1.23]$} & 0.84 & {$[0.59 ; 1.18]$} & $\mathbf{2 . 4 3}$ & {$[\mathbf{1 . 2 5} ; \mathbf{4 . 7 5}]$} \\
& $05-14$ & $\mathbf{0 . 4 9}$ & {$[\mathbf{0 . 3 6} \mathbf{0 . 6 6}]$} & $\mathbf{1 . 8 3}$ & {$[\mathbf{1 . 1 0 ;} \mathbf{3 . 0 6}]$} & 1.42 & {$[0.53 ; 3.80]$} \\
& $14-18$ & 1.00 & {$[0.73 ; 1.35]$} & 1.04 & {$[0.61 ; 1.76]$} & 1.61 & {$[0.54 ; 4.78]$} \\
& $18-25$ & $\mathbf{4 . 7 8}$ & {$[\mathbf{3 . 6 6 ; 6 . 2 6}]$} & $\mathbf{2 . 9 2}$ & {$[\mathbf{1 . 6 8} ; \mathbf{5 . 0 8}]$} & $\mathbf{3 . 0 0}$ & {$[\mathbf{1 . 1 3} ; \mathbf{7 . 9 3}]$} \\
& $25-65$ (ref) & 1 & - & 1 & - & 1 & - \\
Location & $65+$ & $\mathbf{0 . 6 5}$ & {$[\mathbf{0 . 4 9 ; 0 . 8 7 ]}$} & 1.19 & {$[0.71 ; 1.99]$} & 0.95 & {$[0.35 ; 2.60]$} \\
& Dense areas (ref) & 1 & - & 1 & - & 1 & - \\
& Non-dense areas & 1.08 & {$[0.89 ; 1.31]$} & 1.19 & {$[0.84 ; 1.70]$} & 1.64 & {$[0.81 ; 3.32]$} \\
\hline
\end{tabular}

Table 4. Hospitalization rates and ratios by type of road user, gender, age and location; medical Registry and RTS corrected for seasonality, Rhône County, 2005-2006

\begin{tabular}{|c|c|c|c|c|c|c|c|c|}
\hline & & \multicolumn{2}{|c|}{$\begin{array}{c}\text { Car occupants } \\
N=611\end{array}$} & \multicolumn{2}{|c|}{$\begin{array}{c}\text { Pedestrians } \\
N=359\end{array}$} & \multicolumn{2}{|c|}{$\begin{array}{c}\text { Cyclists } \\
N=332\end{array}$} & \multirow{2}{*}{$\begin{array}{l}\text { PTW riders } \\
\qquad=680 \\
\text { Rate }\end{array}$} \\
\hline & & Rate & Ratio & Rate & Ratio & Rate & Ratio & \\
\hline & & \multicolumn{7}{|c|}{ Per 1 million hours } \\
\hline & All & 1.25 & & 1.20 & & 14.81 & & 97.44 \\
\hline \multirow[t]{2}{*}{ Gender } & Male (ref) & 1.35 & 1.0 & 1.38 & 1.0 & 15.69 & 1.0 & - \\
\hline & Female & 1.13 & 0.8 & 1.04 & 0.8 & 11.26 & 0.7 & - \\
\hline \multirow[t]{5}{*}{ Age group } & $05-14$ & 0.57 & 0.6 & 1.77 & 2.0 & 13.12 & 1.1 & - \\
\hline & $14-18$ & 1.60 & 1.8 & 0.69 & 0.8 & 14.04 & 1.2 & - \\
\hline & $18-25$ & 4.69 & 5.3 & 1.00 & 1.1 & 12.25 & 1.0 & - \\
\hline & $25-65$ (ref) & 0.89 & 1.0 & 0.88 & 1.0 & 12.15 & 1.0 & - \\
\hline & $65+$ & 1.40 & 1.6 & 2.05 & 2.3 & 30.83 & 2.5 & - \\
\hline \multirow[t]{6}{*}{ Location } & Dense areas (ref) & 1.04 & 1.0 & 1.16 & 1.0 & 13.40 & 1.0 & - \\
\hline & Non-dense areas & 2.05 & 2.0 & 1.83 & 1.6 & 32.73 & 2.4 & - \\
\hline & & \multicolumn{7}{|c|}{ Per 1 million trips } \\
\hline & All & 0.36 & & 0.14 & & 4.43 & & 28.50 \\
\hline & & \multicolumn{7}{|c|}{ Per 1 million kilometers } \\
\hline & All & 0.05 & & 0.31 & & 1.68 & & 2.68 \\
\hline
\end{tabular}

PTW: powered two-wheeler; - Insufficient data to estimate rates

The serious-injury rates are given in Table 5. Compared with car occupants and with regards to time spent travelling, cyclists had a 16 times higher rate $(\mathrm{p}<0.01)$ and PTW riders had a rate about 120 times higher $(\mathrm{p}<0.01)$; rates for pedestrians and car occupants were similar $(\mathrm{p}=0.7)$. 
Relative to car occupants, cyclists are more likely to be injured, hospitalized, or seriously injured per 1 million trips, kilometers or hours. This is consistent with other studies in France (Gabet 2005; Mercat 2006; Licaj, Haddak et al. 2011), in the United States (Beck, Dellinger et al. 2007), in New Zealand (Tin Tin, Woodward et al. 2010) and in Australia (Garrard, Greaves et al. 2010).

Table 5. Serious-injury (MAIS 3+) rates according to different mobility measures, and ratios by type of road user, gender, age, and location; medical Registry and Road Travel Survey corrected for seasonality, Rhône County, 2005-2006

\begin{tabular}{|c|c|c|c|c|c|c|c|c|}
\hline & & \multicolumn{2}{|c|}{$\begin{array}{c}\text { Car occupants } \\
N=202\end{array}$} & \multicolumn{2}{|c|}{$\begin{array}{c}\text { Pedestrians } \\
N=194\end{array}$} & \multicolumn{2}{|c|}{$\begin{array}{l}\text { Cyclists } \\
N=144\end{array}$} & \multirow{2}{*}{$\begin{array}{l}\text { PTW riders } \\
\qquad \begin{array}{r}N=346 \\
\text { Rate }\end{array}\end{array}$} \\
\hline & & Rate & Ratio & Rate & Ratio & Rate & Ratio & \\
\hline & & \multicolumn{7}{|c|}{ Per 1 million hours } \\
\hline & All & 0.41 & & 0.65 & & 6.42 & & 49.58 \\
\hline \multirow[t]{2}{*}{ Gender } & Male (ref) & 0.51 & 1.0 & 0.78 & 1.0 & 6.74 & 1.0 & - \\
\hline & Female & 0.30 & 0.6 & 0.53 & 0.7 & 5.09 & 0.8 & - \\
\hline \multirow[t]{5}{*}{ Age group } & $05-14$ & 0.21 & 0.7 & 1.01 & 2.2 & 5.98 & 1.1 & - \\
\hline & $14-18$ & 0.43 & 1.5 & 0.36 & 0.8 & 6.42 & 1.2 & - \\
\hline & $18-25$ & 1.67 & 5.8 & 0.49 & 1.1 & 3.60 & 0.7 & - \\
\hline & $25-65$ (ref) & 0.29 & 1.0 & 0.46 & 1.0 & 5.25 & 1.0 & - \\
\hline & $65+$ & 0.43 & 1.5 & 1.17 & 2.5 & 16.44 & 3.1 & - \\
\hline \multirow[t]{6}{*}{ Location } & Dense areas (ref) & 0.36 & 1.0 & 0.63 & 1.0 & 5.72 & 1.0 & - \\
\hline & Non-dense areas & 0.62 & 1.7 & 0.92 & 1.5 & 14.92 & 2.6 & - \\
\hline & & \multicolumn{7}{|c|}{ Per 1 million trips } \\
\hline & All & 0.12 & & 0.07 & & 1.92 & & 14.50 \\
\hline & & \multicolumn{7}{|c|}{ Per 1 million kilometers } \\
\hline & All & 0.02 & & 0.17 & & 0.73 & & 1.36 \\
\hline
\end{tabular}

PTW: powered two-wheeler; ref=reference group; - Insufficient data to estimate rates

With regards to each exposure measure, PTW riders had the highest all-injury, hospitalization, and serious-injury rates. In the present study, the amount of excess risk is quantified and is very high. This result is consistent with other studies in France (Gabet 2005; Mercat 2006; Bernagaud \& Hurez 2011; Licaj, Haddak et al. 2011), in the United States (Beck, Dellinger et al. 2007), and in New Zealand (Tin Tin, Woodward et al. 2010), using police or hospital-based crash data. This high excess of risk is giving cause for much concern.

In the present study, the risk for pedestrians compared to car occupants is not clear; it is very dependent on the choice of exposure and to a smaller extent, on the injury category. Unlike motorcyclists and cyclists, pedestrians share the road to a small extent with car occupants; they are at little risk when they use sidewalks separated from the traffic by parked cars and/or trees. It would be interesting to estimate injury rates for pedestrians restricted to crossing the streets.

Ratios between injury rates for each user type and for car occupants showed differences according to which exposure measure is used. The ratios of injury rates with regards to the number of trips or hours spent were similar, for a given type of user. In contrast, with regards to the kilometer criterion, ratios of injury rates were much higher for cyclists and pedestrians and lower among users of PTW. This discrepancy corresponds to the fact that, for a same duration, car occupants and PTW riders, having a higher average speed, travel a longer distance than pedestrians and cyclists. Time criterion is less elastic since the average time spent travelling a day is quite similar between types of road user. The time budget is hence the most relevant measure for comparisons between individuals, and between means of transport.

\subsubsection{Injury rates by gender}

Injury rates between men and women are provided in Tables 1, 4, 5. Using univariate analyses, rates were similar between genders, except for cyclists, for the all-injury rate, where women have a higher risk. In the multivariate analyses, women did not have higher injury ratio than men, all other things being equal (Table 3 ). By type of road user, for pedestrians and car occupants separately, women did not have higher injury ratios than men (Table 3). For cyclists, women had a twice higher injury ratio than men $(\mathrm{CI}=[1.3 ; 4.8])$. A possible explanation could be that women have on average less experience in cycling than men. However, one can also wonder whether there could be an underestimation of female cycling mobility in the RTS, since this higher risk for women is not found in the literature. Indeed, an American study (Beck, Dellinger et al. 2007) using the 
police-reported crash data selected for the years 1999 to 2003 and the mobility data from the 2001 NTS, male cyclists had 1.7 times higher injury rates than female cyclists. An older American study showed similar male and female rates (288 versus 331 injuries per million bicycle trips), using crash data from Consumer Product Safety Commission's National Electronic Injury Surveillance System in 1990 and mobility data from the 1990 Nationwide Personal Transportation Survey (Li \& Baker 1996).

\subsubsection{Injury rates by age group}

Injury rates by age group are provided in Tables $1,4,5$. Using the univariate analyses, some age groups already appear at higher risks. Using the multivariate analyses (Table 2), the age group 18-25 years had a 4 times higher all-injury ratio $(\mathrm{IR}=3.9 ; \mathrm{CI}=[2.4 ; 6.3])$ compared to the age group 25-65 years, with regards to time spent travelling. The higher risk for the age group 18-25 years was also found separately within the group of car occupants $(\mathrm{IR}=4.8 ; \mathrm{CI}=[3.7 ; 6.3])$, pedestrians $(\mathrm{IR}=2.9 ; \mathrm{CI}=[1.7 ; 5.1])$ and cyclists $(\mathrm{IR}=3 ; \mathrm{CI}=[1.1 ; 7.9]$; Table 3). This excess of injury risk in the age group 18-25 years may correspond to stronger risk-taking behavior and, for car occupants, to a learning process (in France, driving license can be obtained from age 18). The age group 5-14 years had a half lower injury ratio as car occupants $(\mathrm{CI}=[0.4 ; 0.7])$ but had a twice higher ratio as pedestrians $(\mathrm{CI}=[1.1 ; 3.1])$. They are protected in the car compartment, but very often injured as pedestrians (they are in a learning process of the risk). The age group $65+$ years had a lower all-injury rate as car occupants $(\mathrm{IR}=0.7 ; \mathrm{CI}=[0.5 ; 0.9])$ compared to the age group 25-65 years. These results are consistent with an American study and a French one (Mercat 2006; Beck, Dellinger et al. 2007). On the contrary, the age group 65+ years seemed to have higher hospitalization and serious-injury rates for car occupants, pedestrians and cyclists, compared with the age group 25-65 years and with regards to time spent travelling (significative only for pedestrians, for the serious injury rate $(\mathrm{p}=0.03)$, and not significant for others, probably because of low statistical power).

\subsubsection{Injury rates by location}

Cyclists, with regards to time spent travelling, seemed to have a higher injury rates in non-dense areas than in dense areas using univariate analyses (between 2 and 3 times higher, non-significative; Tables 1, 4, 5) or multivariate ones $(\mathrm{IR}=1.6, \mathrm{CI}=[0.8 ; 3.3]$; Table 3$)$. Although not significative, but at the same time, lacking statistical power, a possibly higher risk in non-dense areas could be due to the higher average speed of cyclists in non-dense than in dense areas (resp. 14 vs. $8 \mathrm{~km} / \mathrm{h}$, from the RTS) as well as the higher speed of motor vehicles, potential crash opponents, in non-dense areas compared to dense areas. This would mitigate the common belief that "cycling in urban areas is dangerous", usually implying that it is more secure in rural areas. A higher risk in non-dense areas seems also the case for hospitalization $(I R=2)$ for car occupants $(p=0.052)$. This can also be explained by higher speeds in non-dense areas.

\subsection{Trends}

Trends are provided in figure 1 and 2. For car occupants, the all-injury rate seems to have sligthly decreased between 1996-1997 and 2005-2006 using univariate analyses (multiplied by 0.9, p=0.8; Figure 1) or using multivariate ones $(\mathrm{IR}=0.89, \mathrm{CI}=[0.73 ; 1.10])$. For them, the serious-injury rate also seems to have slightly decreased between 1996-1997 and 2005-2006 using univariate analyses (multiplied by 0.7, p=0.7).

per 1 million hours

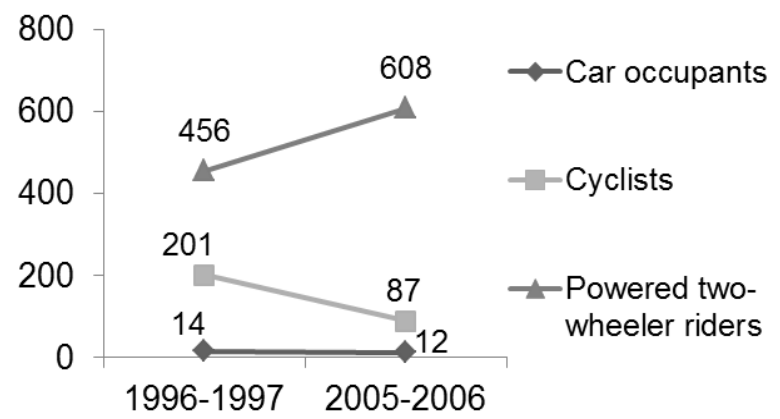

reference 1 in 1996-1997

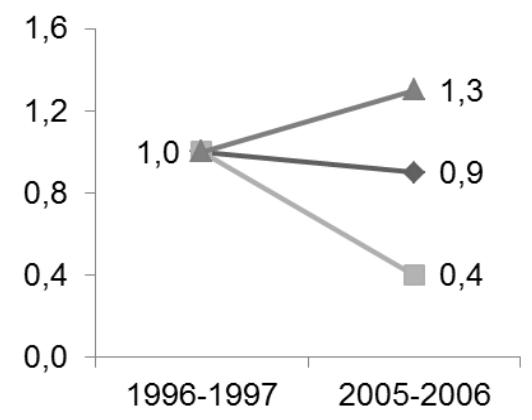

Figure 1 : Trends of the all-injury rates, per 1 million hours, and relative to 1996-1997 (reference 1), medical Registry and RTSs corrected for seasonality, Greater Lyon 

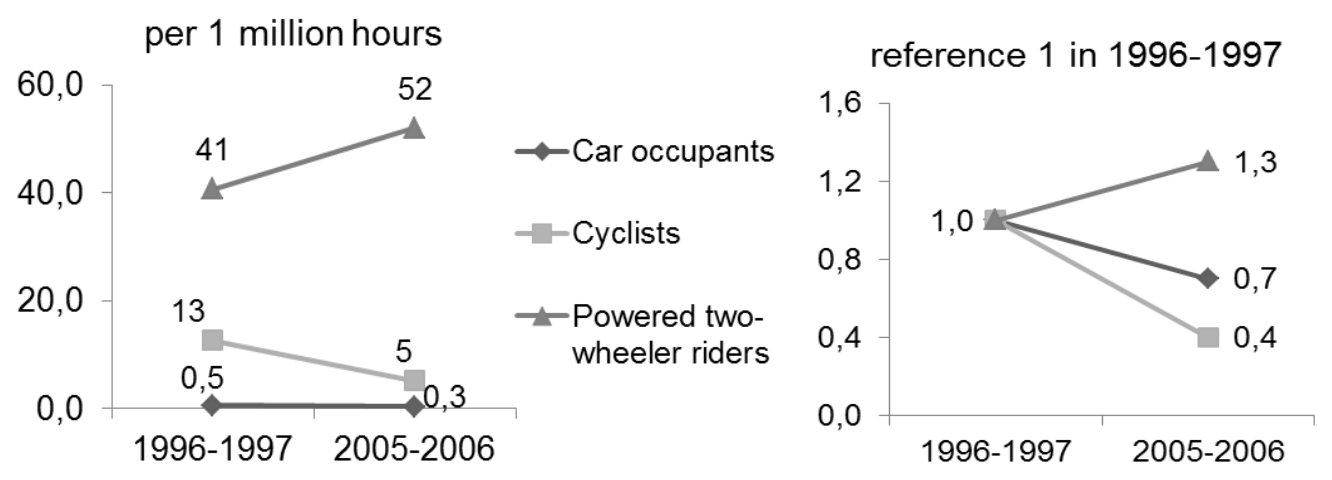

Figure 2: Trends of the serious-injury rates, per 1 million hours,

and relative to 1996-1997 (reference 1), medical Registry and RTSs corrected for seasonality, Greater Lyon

These possible decreases correspond to a similar mobility between the two periods and a slightly decrease in the number of injured car occupants. This slight decrease can be explained by the fact that the period includes years 2003 and 2004 when road safety had been greatly improved in France. There had been a massive installation of automatic speed cameras that led to a decrease in car speeds (ONISR 2005), and hence an improvement in road safety. The small frequencies at the regional level lead to a low statistical power, hence to non-significant trends. For cyclists, the all-injury rate seems to have decreased between the two periods using univariate analyses (multiplied by $0.4, \mathrm{p}=0.0 .7$; Figure 1 ) or using multivariate ones (multiplied by $0.64, \mathrm{CI}=[0.30 ; 1.36]$ ). For them, the serious-injury rate also also seems to decrease between the two periods (multiplied by $0.4, p=0.13$; Figure 2). These possible decreases correspond to an increase in the mobility of cyclists in 2005-2006 compared with 19961997 (it has doubled) and a stagnation in the number of those injured. The decreases in rates seem more marked for cyclists than for car occupants. This tends to indicate the "safety in number" effect for cyclists: the more cyclists there are, the more they are collectively and individually seen, the more car occupants pay attention to them and thus the risk of cyclists being involved in a crash decreases [Jacobsen, 2003].

For PTW riders, the all-injury and serious-injury rates may have slightly increased (both multiplied by 1.3, nonsignificative, using univariate analyses) between 1996-1997 and 2005-2006 in Greater Lyon. This corresponds to a similar mobility between the two periods and a possibly slightly higher number of those injured $(\mathrm{p}=0.82)$ in 2005-2006 compared with 1996-1997. Their average speed has not decreased between the two periods (ONISR 2005). These results reinforce the concern for PTW riders.

\section{Discussion and conclusions}

The Rhône County is quite urbanized with a central city (Lyon) leading to higher risk of crashes but of lower severity. Nevertheless, this county is an average area in terms of mobility compared to France as a whole. Injury rates may be different between regions; but orders of magnitude of ratios between rates by road user types, age categories, males-females or between dense and non-dense areas can be generalized.

\subsection{Study limitations}

There were missing values for some residence locations of the casualties and for some crash locations. These missing values were imputed using simple imputation from proportions estimated on observations without missing-values. The rates for PTW riders by gender, age group and location separately were not estimated: we are concerned about the reliability of the estimates because of small number of PTW trips in the Regional Travel Survey. The mobility data provide information only about residents of the area studied. It would be interesting, however, to know the travel practices of the non-residents.

We were unfortunately not able to estimate confidence intervals of injury rates because of the multiplicity of the estimation steps: estimates from a mobility survey (with a complex design), estimates of seasonality ratios from another survey (with complex design), estimates (counts) of those injured from the Registry, and ratios between estimates. 


\subsection{Study strengths}

This study is among the first in France to study the risk of injury using crash and mobility data (Gabet 2005; Mercat 2006; Bernagaud \& Hurez 2011), and comparing road type users. This is one of the first studies that compare these risks based on crash data from the medical Registry of the Rhône County (Licaj, Haddak et al. 2011). The Rhône road trauma registry is far more complete than the police crash data. The medical registry enables the estimation of rates for various injury categories: all-injury, hospitalization, and serious-injury (MAIS 3+).

The regional and national travel surveys allow us to estimate mobility in three criteria: trips, distance traveled and time spent. The national surveys enable a correction of the RTS that was restricted to the winter season (November to April), on weekdays, outside weekends and public and school holidays. This correction for seasonality appears relevant; indeed, the ratio was around 1.5 for cyclists.

\subsection{Conclusions}

In the present study, the amount of excess risk for PTW riders is quantified and is very high. This high excess of risk is very concerning. Moreover, the potential countermeasures will not be sufficient to fill the huge gap between the risks of PTW riders and car occupants; therefore, the question that arises is: should the use of PTW be deterred?

Although the risk is higher in cyclists than in car occupants, it should not be concluded that cycling has to be deterred. One must take into account the health benefits of this physical activity; these positive effects have been shown to balance and even outweigh the negative effects of road crashes (Andersen, Schnohr et al. 2000; de Hartog, Boogaard et al. 2010; de Nazelle, Nieuwenhuijsen et al. 2011; Rojas-Rueda, De Nazelle et al. 2011; Praznoczy 2012). These studies were however limited to fatalities. A French study, conducted on both those injured and those killed and using a correction for under-reporting of police crash data, showed a better costsbenefit balance for cycling compared with car, for trips up to $10 \mathrm{~km}$ at least (Papon 2002).A French study aiming at estimating fatal rates at the national level has been carried out using fatal crash data from the police and mobility data from the 2007-2008 national household travel survey (NTS) (Bouaoun, Amoros et al. submitted). Exposure-based injury rates can be a tool for monitoring and evaluating the effectiveness of policies and programs, and for comparisons between countries.

\section{Acknowledgments}

We wish to thank all the people who have participated in the data collection and data entry in the framework of the Association for the Registry of road traffic casualties in the Rhône (ARVAC: president E. Javouhey) or in the framework of INRETS-UMRESTTE (B. Laumon, scientific consultant for the registry, A. Ndiaye, medical coordinator, and B. Gadegbeku, data coordinator). This work was funded by the Délégation à la Sécurité et à la Circulation Routières (DSCR).

\section{References}

AAAM (1990). Association for the Advancement of Automotive Medicine, The Abbreviated Injury Scale (1990 revision), Des Plaines, Illinois.

Amoros, E., M. Chiron, B. Thelot and B. Laumon (2011). "The injury epidemiology of cyclists based on a road trauma registry." BMC Public Health 11: 653.

Amoros, E., J. L. Martin and B. Laumon (2006). "Under-reporting of road crash casualties in France." Accident Analysis and Prevention 38(4): 627-635.

Andersen, L., P. Schnohr, M. Schroll and H. Hein (2000). "All-cause mortality associated with physical activity during leisure time, work, sports, and cycling to work." Arch Intern Med 160(11): 1621-1628.

Beck, L. F., A. M. Dellinger and M. E. O'Neil (2007). "Motor vehicle crash injury rates by mode of travel, United States: using exposure-based methods to quantify differences." Am J Epidemiol 166(2): 212-218. 
Bernagaud, A.-S. and C. Hurez (2011). "Comparaison des risques d'accident entre les différents modes." Action Territoriale, Sécurité des déplacements 29.

Bouaoun, L., E. Amoros and M. Haddak (submitted). "Fatal road traffic crashes: comparisons by road user types and measures of exposure ".

de Hartog, J. J., H. Boogaard, H. Nijland and G. Hoek (2010). "Do the Health Benefits of Cycling Outweigh the Risks?" Environ Health Perspect 118(8).

de Nazelle, A., M. J. Nieuwenhuijsen, J. M. Antó, M. Brauer, et al. (2011). "Improving health through policies that promote active travel: A review of evidence to support integrated health impact assessment." Environment International 37(4): 766-777.

Elvik, R. and A. B. Mysen (1999). "Incomplete accident reporting; meta-analysis of studies made in 13 countries." Transportation Research Record 1665: 133-140.

Gabet, P. (2005). Méthode de calcul d'une exposition au risque d'accident en milieu urbain : application de la méthode sur la communauté urbaine de Lille., CERTU-CETE Nord-Picardie.

Garrard, J., S. Greaves and A. Ellison (2010). "Cycling injuries in Australia: Road safety's blind spot?" Journal of the Australian College of Road Safety: 37-43.

Hauer, E. and A. Hakkert (1988). "Extent and some implications of incomplete accident reporting." Transportation Research Record 1185: 1-10.

Langley, J., N. Dow, S. Stephenson and K. Kypri (2003). "Missing cyclists." Injury Prevention 9(4): 376-379.

Li, G. and S. P. Baker (1996). "Exploring the male-female discrepancy in death rates from bicycling injury: the decomposition method." Accid Anal Prev 28(4): 537-540.

Licaj, I., M. Haddak, P. Pochet and M. Chiron (2011). "Contextual deprivation, daily travel and road traffic injuries among the young in the Rhone Departement (France)." Accid Anal Prev 43(5): 1617-1623.

Mercat, N. (2006). Méthode de calcul d'une exposition au risque d'accident en milieu urbain : application de la méthode sur la région urbaine de Grenoble., CERTU-Altermodal.

ONISR (2005). La sécurité routière en France, bilan de l'année 2004. Paris, La documentation Française.

Papon, F. (2002). "La marche et le vélo : quels bilans économiques pour l'individu et la collectivité?" 1ère partie : "le temps et l'argent". Transports 412: 84-94. 2ème partie : "la santé et la sécurité". Transports 413: 187197. 3ème partie : "la collectivité". Transports 414: 232-242.

Papon, F. and R. De Solère (2010). "Les modes actifs : marche et vélo de retour en ville." La revue, Commissariat général au développement durable - Service de l'observation et des statistiques.

Praznoczy, C. (2012). Les bénéfices et les risques de la pratique du vélo - Evaluation en Ïle-de-France, Observatoire Régional de la Santé Ile-de-France: 163.

Rojas-Rueda, D., A. De Nazelle, M. Tainio and M. J. Nieuwenhuijsen (2011). "The health risks and benefits of cycling in urban environments compared with car use: health impact assessment study." British Medical Journal 343.

Tin Tin, S., A. Woodward and S. Ameratunga (2010). "Injuries to pedal cyclists on New Zealand roads, 19882007." BMC Public Health 10: 655. 